\title{
Role of Brain Biomarkers S-100-Beta and Neuron-Specific Enolase for Detection and Follow-Up of Hepatic Encephalopathy in Cirrhosis before, during and after Treatment with L-Ornithine-L-Aspartate
}

\author{
Hendrik Strebel ${ }^{a, b}$ Bernhard Haller ${ }^{c}$ Maximilian Sohn ${ }^{d}$ Wolfgang Schepp ${ }^{a}$ \\ Felix Gundling a, e \\ ${ }^{a}$ Department of Gastroenterology, Hepatology and Gastrointestinal Oncology, Bogenhausen Academic Teaching \\ Hospital, Technical University of Munich, Munich, Germany; ${ }^{b}$ Department for Internal Medicine I, Elblandklinikum, \\ Meißen, Germany; ${ }^{C}$ Institute of Medical Informatics, Statistics and Epidemiology, Klinikum rechts der Isar, \\ Technische Universität München, Munich, Germany; ${ }^{d}$ Klinik für Allgemein-, Viszeral-, Endokrine und \\ Minimal-invasive Chirurgie, Klinikum Bogenhausen, Technische Universität München, Munich, Germany; \\ eDepartment for Gastroenterology, Diabetics and Endocrinology, Kemperhof Hospital, Gemeinschaftsklinikum \\ Mittelrhein, Koblenz, Germany
}

Keywords

Cirrhosis · Critical flicker frequency $\cdot$ Hepatic encephalopathy · L-ornithine-L-aspartate $\cdot$ Neuron-specific enolase · PSE-testing · S-100-beta - West-Haven criteria

\section{Abstract}

Introduction: Hepatic encephalopathy $(\mathrm{HE})$, in the context of liver cirrhosis, seems to result from low-grade cerebral edema of the astrocytes. Serum brain biomarkers S-100-beta und neuron-specific enolase (NSE) are often elevated in brain injury. We hypothesized that neuromarkers S-100-beta and NSE can be used in the diagnosis of HE, compared with standardized diagnostic tools. Material and Methods: A prospective non-randomized intervention study was performed using L-ornithine-L-aspartate (LOLA) for HE treatment. Primary endpoint was the evaluation of neuromarkers

\begin{tabular}{ll}
\hline KARGER & (c) 2020 Sociedade Portuguesa de Gastrenterologia \\
& Published by S. Karger AG, Basel \\
karger@karger.com & This article is licensed under the Creative Commons Attribution- \\
www.karger.com/pjg & $\begin{array}{l}\text { NonCommercial-NoDerivatives 4.0 International License (CC BY- } \\
\text { NC-ND) (http://www.karger.com/Services/OpenAccessLicense). } \\
\text { Usage and distribution for commercial purposes as well as any dis- } \\
\text { tribution of modified material requires written permission. }\end{array}$ \\
BOPEN ACCESS &
\end{tabular}

S-100-beta and NSE for detection and diagnosis of follow-up of $\mathrm{HE}$. As secondary endpoints, the efficacy of LOLA on the course of HE and the diagnostic role of Portosystemic-Encephalopathy-Syndrome score (PHES) and critical flicker frequency (CFF) were analyzed. For diagnosis of covert (CHE) and overt (OHE) HE, West-Haven criteria (WHC), PHES and CFF were assessed at study entry. LOLA was applied (20 g i.v.) for 6 days. At the end of the study, HE evaluation was repeated. S-100-beta, NSE and ammonia were assessed in each patient before, during and after therapy with LOLA. Results: 30 patients were included. At study entry, CHE was diagnosed in $50 \%$ and $\mathrm{OHE}$ in $50 \%$ of all subjects. A total of 25 participants completed the study. After LOLA therapy, deterioration of HE occurred in $<11 \%$, while most patients showed improvement (e.g. improved CFF in 79\%). No significant correlation with HE severity (as diagnosed by WHC, PHES and CFF) could be demonstrated for any biochemical parameter. 
In addition, there were no significant changes in brain biomarkers during the treatment period. Discussion: While CFF as well as PHES showed good correlation with treatment response, S-100-beta and NSE did not significantly correlate with HE severity compared to proven diagnostic methods, and do not seem reliable biochemical markers for the followup under therapy. $\odot 2020$ Sociedade Portuguesa de Gastrenterologia Published by S. Karger AG, Basel

\section{Papel dos biomarcadores cerebrais S-100-beta e enolase neurónio-específica para a deteção e vigilância da encefalopatia hepática na cirrose antes, durante e após terapêutica com L-ornitina- L-aspartato}

\section{Palavras Chave}

Cirrose - Critical flicker frequency - Encefalopatia hepática . L-ornitina-L-aspartato · Enolase neurónio-específica .

PSE-testing · S-100-beta $\cdot$ West-Haven criteria

\section{Resumo}

Introdução: A encefalopatia hepática (EH) na cirrose é vista como o resultado de edema cerebral de baixo grau dos astrócitos. Biomarcadores cerebrais serológicos S-100-beta e enolase neurónio-específica (NSE) estão frequentemente elevados na lesão cerebral. A nossa hipótese é que os neuromarcadores S-100-beta e NSE podem ser usados no diagnóstico de $\mathrm{EH}$, quando comparados com os meios diagnósticos standard. Material e Métodos: Estudo prospectivo não randomizado foi realizado usando L-ornitina-L-aspartato (LOLA) no tratamento da EH. O endpoint primário foi a avaliação dos neuromarcadores S-100-beta e NSE para a deteção e vigilância da EH. Foram endpoints secundários a eficácia da LOLA no curso da EH e o papel diagnóstico do Portosystemic-Encephalopathy-Syndrome score (PHES) e do critical flicker frequency (CFF). Para o diagnóstico de EH oculta (EHO) ou declarada (EHD) foram avaliados os West-Haven criteria (WHC), PHES e CFF à entrada do estudo. LOLA foi administrada ( $20 \mathrm{~g}$ ev) por 6 dias. No fim do estudo os testes de EH foram repetidos. Os níveis de S-100-beta, NSE e amónia foram avaliados em todos os doentes antes, durante e após a terapêutica com LOLA. Resultados: Foram incluídos 30 doentes no estudo. À entrada EHO foi diagnosticada em 50\% e EHD nos restantes $50 \%$ dos participantes. Um total de 25 doentes completaram o estudo. Após a terapêutica com LOLA, verificou-se deterioração da $\mathrm{EH}$ em $<11 \%$, enquanto a maioria dos doentes melhorou (melhoria CFF em 79\%). Não se demonstrou nenhuma correlação significativa com a gravidade da EH (tendo em conta os WHC, PHES e (FF) para nenhum dos parâmetros bioquímicos. Para além disso, não se demonstraram variaões significativa nos biomarcadores cerebrais durante o período de tratamento. Discussão: Apesar do CFF e do PHES apresentarem boa correlação com a resposta terapêutica, a S-100-beta e a NSE não se correlacionaram significativamente com a gravidade da $\mathrm{EH}$ quando comparado com os outros métodos diagnósticos standard, não parecendo ser marcadores bioquímicos úteos para a vigilância da resposta terapêutica.

(C) 2020 Sociedade Portuguesa de Gastrenterologia Publicado por S. Karger AG, Basel

\section{Introduction}

Hepatic encephalopathy (HE) is one of the major complications of liver cirrhosis which is characterized by a heterogeneous complex of psychomotoric symptoms. These different clinical grades were defined in the West-Haven criteria (WHC, 1-5). HE includes all neurological-psychiatric disorders resulting from acute to chronic liver diseases mostly under the influence of precipitating factors (e.g. gastrointestinal bleeding or infections). HE represents a continuum with a clinical spectrum ranging from minor cognitive deficits (covert HE, $\mathrm{CHE}$ ) to coma. A clinically manifest $\mathrm{HE}$ (also named overt $\mathrm{HE}, \mathrm{OHE}$ ) occurs in about $30-45 \%$ of all cirrhotic patients, while CHE can be diagnosed in up to $80 \%$ when using additional diagnostic tools [1-5]. HE is often associated with decompensated cirrhosis and an unfavorable prognosis [6-8]. However, the exact prevalence of $\mathrm{HE}$ is difficult to determine due to differences in etiology, severity and diagnostic tools which are used [9]. Since the number of patients with cirrhosis is expected to increase in the upcoming years due to the obesity epidemic resulting in NASH-induced cirrhosis [9-10], there is a strong need for reliable and fast diagnostic tools for HE diagnosis.

In addition to its prognostic significance, $\mathrm{HE}$ causes numerous negative effects, e.g. impaired driving skills, reduced intellectual performance and decreased quality of life [11-17]. This underlines the importance of timely and rapid diagnostic procedures for $\mathrm{HE}$ to start specific $\mathrm{HE}$ treatment as soon as possible. The benefits of an adequate HE therapy (e.g. by application of lactulose, rifaximin or L-ornithine-L-aspartate, LOLA) are well documented in 
Table 1. Baseline parameters of all cirrhotic patients included in this study

\begin{tabular}{lcc}
\hline Baseline parameters & $\begin{array}{l}\text { Covert HE (CHE) } \\
(n=15)\end{array}$ & $\begin{array}{l}\text { Overt HE (OHE) } \\
(n=15)\end{array}$ \\
\hline Age (SD), years & $55.6(9.9)$ & $62.7(7)$ \\
Sex (male/female) & $8 / 7$ & $7 / 8$ \\
Alcohol-related cirrhosis, $n(\%)$ & $12 / 15(80)$ & $10 / 15(87)$ \\
Ascites & $13 / 15(87)$ & $10 / 15(67)$ \\
Median serum bilirubin level (SD), mg/dL & $6.4(7.2)$ & $4.0(4,2)$ \\
\hline
\end{tabular}

numerous prospective studies, demonstrating e.g. a lower rate of inpatient hospital stays [18-19].

Time-consuming diagnostic procedures such as the Portosystemic-Encephalopathy-Syndrome score (PSEtest) and neurophysiologic testing are not available everywhere and imply sometimes difficulties concerning interpretation of test results [20]. Therefore, laboratory chemical parameters are of special interest for detection and grading of HE [21, 22]. However, the significance of widespread tests such as the ammonia determination for detection and follow-up of the HE is considered as being not reliable enough $[5,22,23]$.

Imaging studies using proton magnetic resonance spectroscopy (H-MRS) on the human brain in patients with cirrhosis and HE could demonstrate the presence of a mild brain edema, which deteriorates under the influence of precipitating factors triggering neurological-psychiatric symptoms of HE via functional disturbances of the astrocytes [24]. Of note, astrocyte swelling is regarded as an important cornerstone of pathophysiology of HE. A multitude of different factors including ammonia, benzodiazepines and inflammatory cytokines can worsen this condition $[24,25]$.

$\mathrm{HE}$ in cirrhosis is seen as the clinical manifestation of astrocyte swelling resulting in a low-grade cerebral edema caused by different precipitating factors $[24,25]$. Therefore, neuromarkers which are set free by cellular swelling in the brain may serve possibly as diagnostic markers to detect and quantificate HE. The calcium-binding protein S-100-beta is a protein found primarily in the nervous system of vertebrates, which is significantly elevated in serum, urine and cerebrospinal fluid in cases of neuronal damage [26-29]. This brain biomarker is used e.g. in the evaluation of the prognosis of patients after ischemic cerebral infarction or to assess neuropsychological deficits following craniocerebral trauma [26-28]. Wiltfang et al. [30] analyzed the impact of S-100-beta in serum as a surrogate marker for neuronal damage in $\mathrm{HE}$ patients with cirrhosis and transjugular intrahepatic portosystemic stent shunt (TIPSS) finding a positive correlation. To date, there is more promising data regarding its diagnostic impact, e.g. in children with acute liver failure [31-33]. Another serum marker for cerebral damage is neuronspecific enolase (NSE), a glycolytic enzyme inside of neuronal and neuroendocrine cells. NSE is used as a tumor marker and as a prognostic parameter for cerebral damage (e.g. hypoxic brain damage of ICU patients). One study describes elevated serum levels of NSE in fulminant liver failure while other studies conclude that in chronic liver diseases no diagnostic or prognostic value can be attributed to this parameter $[41,42]$.

Despite of all these promising data, it is not clear, whether neuromarkers S-100-beta and NSE can be used as reliable biomarkers in the detection and follow-up of HE. Of note, there are no prospective intervention studies using standardized diagnostic tools so far.

Therefore, this prospective study evaluated whether brain biomarkers S-100-beta and NSE coincide with HE (as diagnosed by WHC, PSE-testing and critical flicker frequency $[\mathrm{CFF}]$, respectively) before, during and after specific medical therapy using LOLA. LOLA is a mixture of two endogenous amino acids (L-ornithine and L-aspartate) and represents an effective HE therapy [34]. These neuromarkers might be associated with the severity and course of HE under specific therapy.

\section{Material and Methods}

30 patients with liver cirrhosis (confirmed histologically and/ or by imaging) and HE between 18 and 75 years of age were included in this prospective study. Patients with other diseases or conditions (e.g. intracranial hemorrhage, apoplexy) causing possibly a change of brain biomarkers S-100-beta and NSE were excluded.

Successful therapy of trigger factors (e.g. acute bleeding or infection) often results in an improvement of HE, independent from any specific therapeutic intervention. To avoid any additional positive effect on HE improvement under LOLA therapy, patients with proven trigger factors for an HE episode were excluded.

Most patients included in the present study were admitted to our hospital because of an acute ascitic fluid decompensation. The 
Table 2. West Haven criteria (WHC) and clinical description (adapted from [4-5])

\begin{tabular}{|c|c|c|}
\hline WHC including MHE & ISHEN & Description \\
\hline Unimpaired & & No encephalopathy at all, no history of HE \\
\hline Minimal & Covert & $\begin{array}{l}\text { Psychometric or neuropsychological alterations of tests exploring } \\
\text { psychomotor speed/executive functions or neurophysiological } \\
\text { alterations without clinical evidence of mental change }\end{array}$ \\
\hline Grade I & Covert & $\begin{array}{l}\text { Trivial lack of awareness } \\
\text { Euphoria or anxiety } \\
\text { Shortened attention span } \\
\text { Impairment of addition or subtraction } \\
\text { Altered sleep rhythm }\end{array}$ \\
\hline Grade II & Overt & $\begin{array}{l}\text { Lethargy or apathy } \\
\text { Disorientation for time } \\
\text { Obvious personality change } \\
\text { Inappropriate behavior } \\
\text { Dyspraxia } \\
\text { Asterixis }\end{array}$ \\
\hline Grade III & Overt & $\begin{array}{l}\text { Somnolence to semi-stupor } \\
\text { Responsive to stimuli } \\
\text { Confused } \\
\text { Gross disorientation } \\
\text { Bizarre behavior }\end{array}$ \\
\hline Grade IV & Overt & Coma \\
\hline
\end{tabular}

ISHEN, International Society for Hepatic Encephalopathies and Nitrogen Metabolism; MHE, minimal hepatic encephalopathy.

entire etiologic spectrum of cirrhosis was included in this study. Baseline parameters of all patients are shown in Table 1.

Specific HE therapy with LOLA was applied if OHE could be diagnosed on the basis of clinical symptoms (WHC) or if CHE was diagnosed by several diagnostic tools (psychometric and neurophysiological tests: PSE-testing, CFF).

The two endogenous amino acids L-ornithine and L-aspartate can be administered orally or parenterally as a specific HE medication. Proven effect of LOLA medication has been shown in numerous randomized clinical trials [34]. The benefits of LOLA, e.g. regarding lowering of blood ammonia and improving HE symptoms, have been known for 50 years. Within that time, numerous randomized clinical trials and recent meta-analysis have been performed to establish the efficacy of LOLA for the treatment of HE in cirrhosis [34].

In this study, therapy was exclusively administered with $20 \mathrm{~g}$ LOLA per day which was applied intravenously for a period of 6 days. This substance was chosen because its effectiveness has been proven in several studies [34] and since a safe and guaranteed application is possible by intravenous application. Other specific forms of HEtreatment were excluded (e.g. application of lactulose or rifaximin).

\section{Assessment of HE Severity}

West-Haven Criteria

Classification of the different grades of HE was performed according to international accepted clinical criteria (WHC, Table 2; adapted from [4]).
In addition to clinical assessment, grading of HE was performed by several standardized diagnostic tools (PSE-testing, CFF).

Critical Flicker Frequency

CFF was determined as it was described elsewhere (using Hepatonorm TM Analyzer ${ }^{\circledR}$, Düsseldorf, Germany) [35].

To identify abnormal CFF we used the same threshold of an abnormal CFF of $39 \mathrm{~Hz}$ as this was defined in the pilot study by Kircheis et al. [35]. Kircheis et al. found an average CFF of $36.0 \pm$ $1.4 \mathrm{~Hz}$ in subjects with HE 1 (according to WHC) while the average CFF in subjects with $\mathrm{HE} 2$ (according to WHC) was $32.1 \pm 2.7$ $\mathrm{Hz}$ and $\mathrm{HE} 3$ (according to WHC) was $<30 \mathrm{~Hz}$ [35].

\section{PSE-Testing}

While the diagnosis of OHE is based on the clinical picture, psychometric and neurophysiological tests are required to detect the clinical subtle spectrum of CHE. From the large number of test procedures used for diagnosis of $\mathrm{HE}$, the quantitative assessment of portosystemic encephalopathy (PSE-score or PSE-testing) by Schomerus and colleagues has proved to be particularly sensitive [36-39]. Due to the simple feasibility of these test procedures, they represent a widely used method for the diagnosis and grading of low-grade stages of HE. In this study, PSE-testing according to Schomerus and colleagues was used $\left({ }^{\circledR} 1999\right.$ Swets \& Zeitlinger B.V, Swets Test Services, Frankfurt). This test consists of 5 differ- 


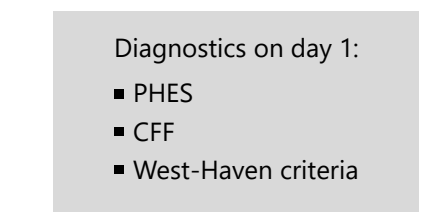

Diagnostics on day 1 :

- PHES

- West-Haven criteria
Diagnostics on day 6 :

- PHES

- CFF

- West-Haven criteria

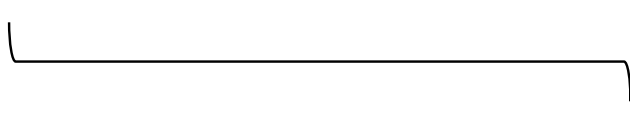

Assessment of biochemical parameters S100beta, NSE and serum ammonia before (day 1), during (day 2-5) and after (day 6) LOLA-therapy

* Drop out: in 4 cases by patient request, 1 death by massive esophageal variceal bleeding.

NSE $=$ Neuron specific enolase

LOLA = L-ornithin-L-aspartate

Fig. 1. Study algorithm.

ent test procedures. In the ZVA test, numbers must be linked as quickly as possible in their arithmetical order. In the more sensitive second numerical connection test (ZVB), numbers and letters must be connected alternately (1-A-2-B-3-C, etc.). In the number symbol test (ZST), different symbols must be assigned to certain numbers as quickly as possible. In the line follow-up test (LNT), the patient must use a pencil to drive down a $5 \mathrm{~mm}$ wide road system as quickly as possible without crossing the boundary lines. The task of puncturing circles (KP) can also be carried out quickly, allowing the psychomotor system to be tested in the same way as with the LNT. Performance and interpretation of this test system was carried out and evaluated according to the relevant manual published by Schomerus and colleagues [36-39].

\section{Assessment of Biochemical Parameters}

Before (day 1), during (day 2-5) and after (day 6) LOLA-therapy, 3 different serum markers were assessed in each subject. These were the brain biomarkers S-100-beta and NSE. Furthermore, plasma ammonia levels were obtained regularly (on day 1-6). All laboratory parameters were measured according to standardized laboratory measurements. The study algorithm is summarized in Figure 1.

\section{Calcium-Binding Protein S-100-Beta}

To measure plasma S-100-beta, peripheral venous blood samples were obtained using the commercial S-100-beta-assay kit (Roche Diagnostics GmbH, Mannheim, Germany). This is an electrochemiluminescence immunoassay (ECLIA) for the quantitative determination of S-100-beta which works according to the sandwich principle. A complex is formed from S-100-beta protein and two antibodies directed against S-100. One (biotinylated) antibody binds (in several intermediate steps) to a solid phase while the other antibody is conjugated with a ruthenium complex. The sample can be assessed by chemiluminescence by measuring the resulting light with a photomultiplier which is proportional to the S-100 concentration. According to the manufacturer, the measuring range is $0.005-39 \mu \mathrm{g} / \mathrm{L}$ (product information S-100-beta, Roche Diagnostics GmbH, Mannheim, Germany) while the normal value for healthy adults is $0.048 \mu \mathrm{gI} / \mathrm{L}$. The 95th percentile value (cutoff between norm value and pathological result) is $0.105 \mu \mathrm{g} / \mathrm{L}$.

\section{Neuron-Specific Enolase}

To measure plasma NSE, peripheral venous blood samples were obtained using a commercial ECLIA assay kit. Measurement of NSE was carried out according to the test procedure described above. According to the manufacturer, the measuring range is $0.050-370$ $\mathrm{ng} / \mathrm{mL}$ (product information NSE, Roche Diagnostics $\mathrm{GmbH}$, Mannheim, Germany) while the standard value is $17 \mathrm{ng} / \mathrm{mL}$.

\section{Ammonia}

To measure plasma ammonia, peripheral venous blood samples were obtained and analyzed within 30 min after withdrawal with routine laboratory methods under standardized laboratory conditions. Normal values were defined as follows: ammonia 12$55 \mu \mathrm{mol} / \mathrm{L}$.

\section{Statistical Analysis}

In order to enable a comparison of the various diagnostic methods mentioned above, it was necessary to classify the patient population into HE severity levels. The severity of $\mathrm{HE}$ was first categorized according to the WHC. All patients with HE were divided into two subgroups: CHE (HE grade 1 according to WHC) and OHE (all other severities HE grade $>1$ according to WHC). The $\mathrm{CHE}$ group was compared with the OHE group before and after the end of therapy and the results within a group before and after therapy. 
Fig. 2. Assessment of HE using CFF. Mean values with standard deviation for the $\mathrm{CHE}$ group and the OHE group before and after application of LOLA therapy for 6 days. The red line shows the CFF-limit value at $39 \mathrm{~Hz}$ which defines the pathological threshold.

Fig. 3. Assessment of HE using PSE-testing. Mean values with standard deviation for PSE-score in the CHE group and the OHE group before (at study entry) and after (at study end) application of LOLA therapy for 6 days.
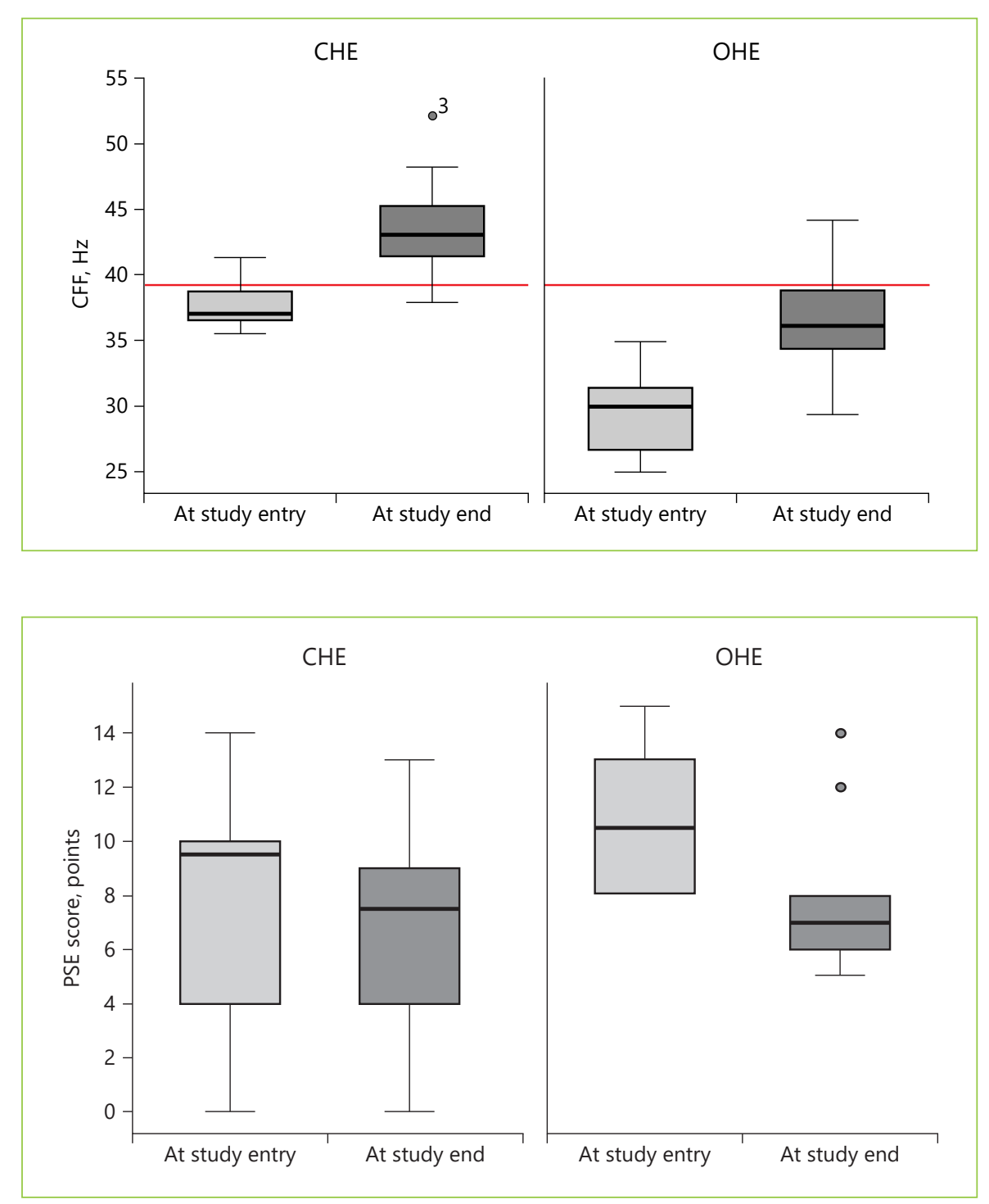

Statistical analysis was performed descriptively using statistical software R version 2.12.0 (R Development Core Team (R: a language and environment for statistical computing. R Foundation for Statistical Computing, Vienna, Austria, 2010, http://www.Rproject.org/). Qualitative data are presented as absolute and relative frequencies, quantitative data as mean, median, minimum and maximum. Qualitative data are presented as absolute and relative frequencies, quantitative data as mean, median, standard deviation, minimum and maximum. Exact $95 \%$ confidence intervals based on the binomial distribution were estimated for the misclassification error rates of the WHC, PSE and CFF. The design of the study did not include a control group of healthy individuals. Therefore, no values for specificity and predictive values referring classification of HE versus no HE could be calculated. For differences between $\mathrm{CHE}$ and OHE group, the following statistical tests were performed: Mann Whitney U test (at days 1-6 of LOLA treatment). For differences during treatment period for both subgroups, Wilcoxon signed rank test (day 1 vs. day 6 of LOLA treat- ment) was carried out. When calculating sensitivity, specificity and predictive values (NPV and PPV) for classification of CHE versus OHE in patients with $\mathrm{HE}$, cross-tables with the corresponding measurements results for the marker S-100-beta (for a cut value of $0.105 \mu \mathrm{g} / \mathrm{L}$ ), NSE (for a cut value of $17 \mathrm{ng} / \mathrm{mL}$ ) and for ammonia (for a cut value of $50 \mu \mathrm{mol} / \mathrm{L}$ ) were carried out.

\section{Results}

The study population consisted of 30 patients (male: 15, female: 15) with proven liver cirrhosis (by imaging criteria and/or histology). The average age was 63.5 years. Altogether, 25 study participants completed the study according to the study protocol. 5 study participants had to be excluded (in 4 cases by patient request, 1 death by mas- 
sive esophageal variceal bleeding). Baseline parameters of all cirrhotic patients included in this study are summarized in Table 1.

\section{Severity of HE before and after Treatment with LOLA} over 6 Days (Using WHC, CFF, PSE-Test)

At study entry (baseline: before administration of LOLA therapy), CHE was diagnosed in 50\% (15/30) compared to OHE in 50\% (15/30) when using clinical criteria (WHC).

At baseline, pathological CFF values (as defined by $\mathrm{CFF}<39 \mathrm{~Hz}$ ) were observed in 27 out of 30 patients In the CHE subgroup, pathological values were obtained in $11 / 15$ cases (sensitivity $80 \%$; median flicker frequency of $36.9 \mathrm{~Hz}$ [range $35.5-41.3 \mathrm{~Hz}$; SD: 1.6]). In the OHE group, CFF was reduced in all subjects (15/15; median flicker frequency of $30.2 \mathrm{~Hz}$ [range 25-35 Hz; SD 3.1]. The difference between the two groups was statistically significant $(p<0.001)$.

When CFF testing was repeated at the end of the study (after 6 days of LOLA therapy), only 7\% in the CHE group (1/15) showed pathological values. In the OHE group, $90 \%$ of patients ( 9 of the 10 remaining patients) showed a decreased CFF (below the threshold value of $<39 \mathrm{~Hz}$ ).

At the end of the study, median CFF was improved in all patients (in CHE: $43 \mathrm{~Hz}$ [range 37-51 Hz; SD 3.5]; in OHE: $36.1 \mathrm{~Hz}$ [range $29.4-44.2 \mathrm{~Hz}$; SD 4.1]). The CFF difference between the two groups remained statistically significant $(p<0.001)$. The improvement of CFF after LOLA therapy was also significant in both groups (CHE: $p=0.001$, OHE: $p=0.005$, Fig. 2 ).

When HE was diagnosed using PHES, patients with CHE showed a pathological score of 11 (threshold value $\leq-4$ ) at initial testing (sensitivity 73\%). At the time of study entry, the median PSE-score values for patients with CHE were -9 (range 0 to -14 ; median -7.7 ; SD 4.1). In patients with $\mathrm{OHE}$, the results were consistently pathologically below the threshold value (sensitivity 100\%). In the OHE group, the median score was -12 was found (range -8 to -15 ; median -11.5; SD 2.4). At the end of therapy, pathological test results could be obtained in $64 \%$ of patients with CHE and in $100 \%$ of patients with OHE. The difference between the two groups was statistically significant $(p=0.007)$. After therapy, a median of -7.5 score points (range 0 to -13; median -6.6; SD 3.9) was found in the CHE group. In the OHE group the median was -7 (range -5 to -14 ; median -8 ; SD 2.8). A significant improvement of the PSE-score could be demonstrated after completion of LOLA therapy $(p=0.016)$. The mean values of all patients with $\mathrm{CHE}$ and $\mathrm{OHE}$ are shown in Figure 3.

S-100-Beta and NSE for Detection and Follow-Up of Hepatic Encephalopathy

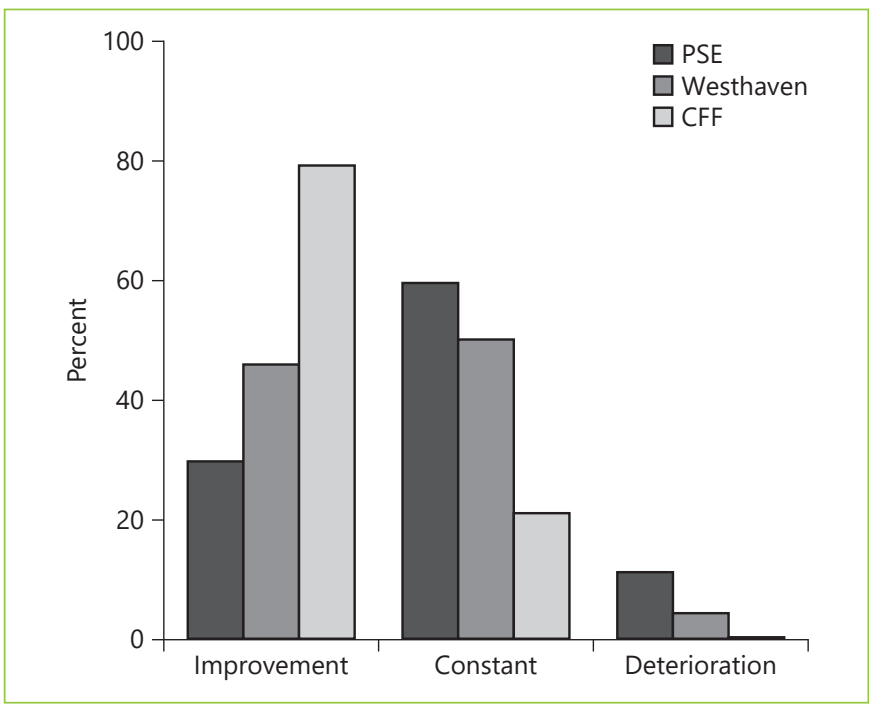

Fig. 4. Change in diagnostic parameters applied after therapy with LOLA over 6 days. PSE, Portosystemic Encephalopathy score; $\mathrm{CFF}$, critical flicker frequency analysis.

\section{Comparison of Different Diagnostic Approaches}

(WHC, CFF and PSE-Testing) for Follow-Up of HE after Completion of LOLA Therapy

In HE patients, LOLA therapy was applied intravenously (20 g) for 6 days. At the end of the study, HE testing was repeated (WHC, PSE-test, CFF). Using WHC, $46 \%$ showed an improvement of clinical symptoms, while $50 \%$ were unchanged and $4 \%$ showed a higher clinical HE stage. Using CFF, 79\% showed an improvement, while $21 \%$ demonstrated an unchanged severity. When using the PSE-test, 30\% were improved, 59\% unchanged and $11 \%$ showed deteriorated test results (Fig. 4).

In a paired comparison of the different diagnostic methods used for detection and follow-up of HE, the best correlation with WHC could be achieved by CFF ( $p=$ 0.001 [initial], $p=0.042$ [final]), while PSE-score showed no significant correlation with WHC and CFF ( $p=0.149$ [initial], $p=0.773$ [final]).

Role of Brain Biomarkers S-100-Beta and NSE for Detection and Follow-Up of HE in Cirrhosis before, during and after Therapy with LOLA

All biochemical parameters investigated in this study (S-100-beta, NSE, ammonia) did not correlate significantly with the severity of HE (as diagnosed by WHC, CFF and PSE-testing). In addition, the mean value analysis (MVA) did not reveal any significant change of the different laboratory parameters over the treatment period of 6 days with LOLA (Fig. 5a-c).

GE Port J Gastroenterol 2020;27:391-403 


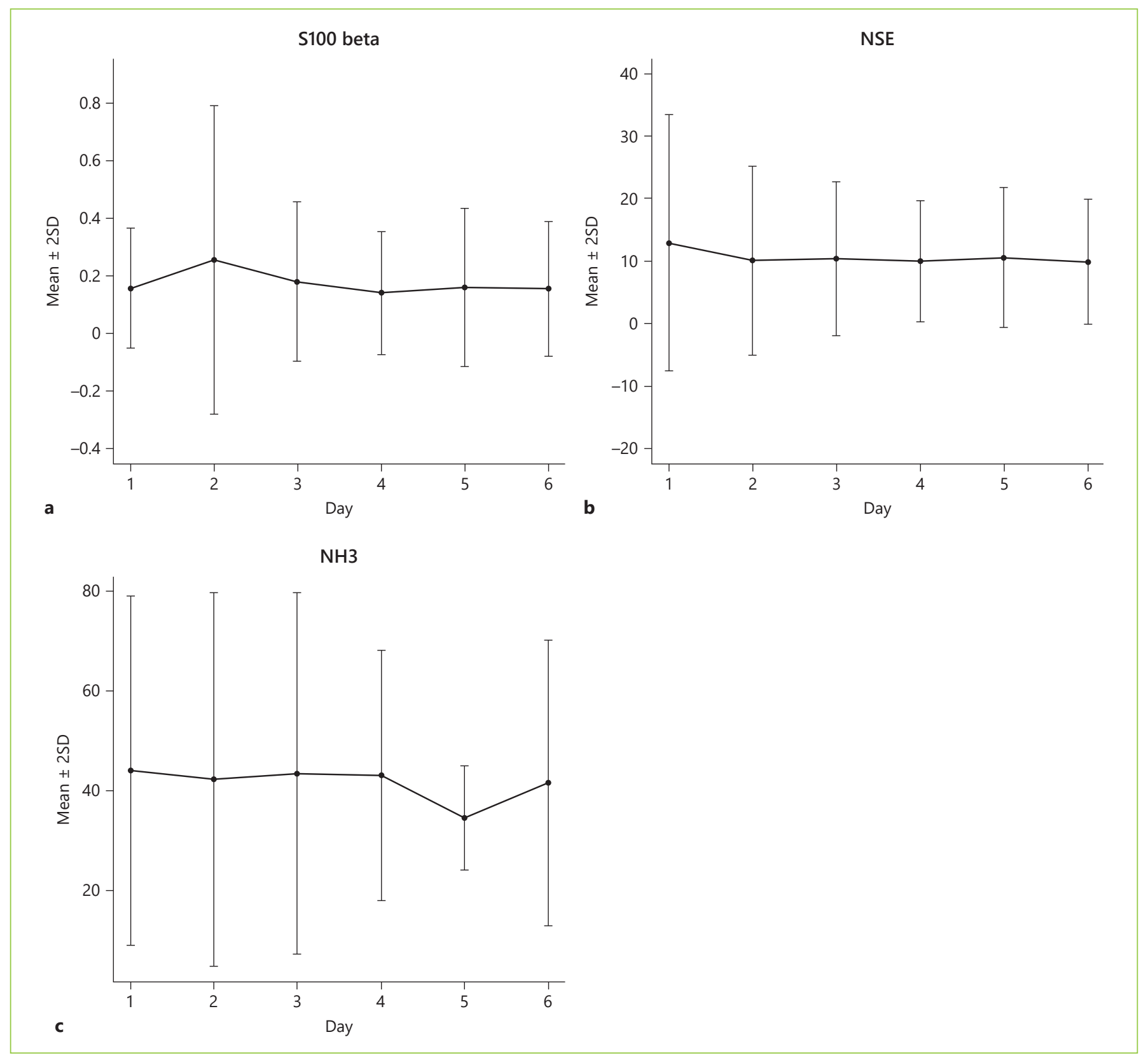

Fig. 5. a-c MVA (mean value analysis) showing no significant change of serum parameters (a S-100-beta, b NSE and $\mathbf{c}$ ammonia) over the treatment period of 6 days with LOLA.

\section{S-100-Beta}

At study entry, increased values of S-100-beta could be detected in $19 / 30$ patients $(>0.105 \mu \mathrm{g} / \mathrm{L}$, sensitivity $63 \%)$. In subjects with $\mathrm{CHE}$, increased values were detected in $7 / 15$ patients (sensitivity $46 \%$ ) compared to $12 / 15$ in patients with OHE (sensitivity $80 \%$, Fig. 6). Multivariate analysis of all data over the 6-day study period revealed no significant changes over time while no differences be- tween the different HE grades were observed. When calculating sensitivity, specificity and predictive values (PPV, NPV) for classification of CHE versus OHE in patients with $\mathrm{HE}$, cross-table with the corresponding measurements results for S-100-beta (for a cut value of 0.105 $\mu \mathrm{g} / \mathrm{L})$ revealed sensitivity of $80 \%$ and specificity of $53 \%$ (PPV 63\%, NPV 73\%; Table 3). 


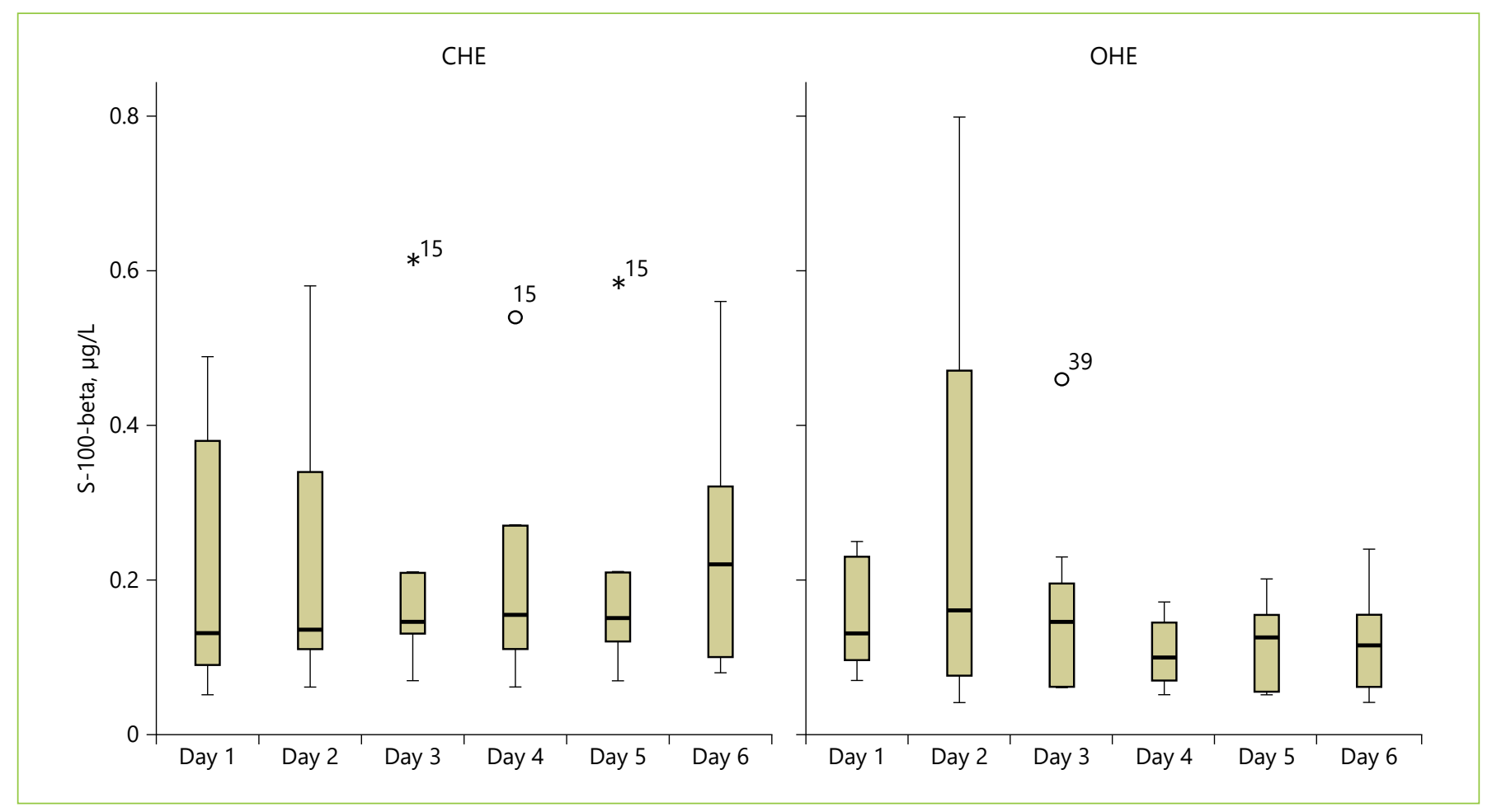

Fig. 6. Follow-up of S-100-beta values showing median and standard deviation in patients with CHE and OHE from day 1-6 while receiving LOLA therapy.

Table 3. Sensitivity, specificity, and predictive values (NPV, PPV) of S-100-beta, NSE and serum ammonia

\begin{tabular}{lllll}
\hline & Sensitivity & Specificity & NPV & PPV \\
\hline S-100-beta & $80 \%$ & $53 \%$ & $73 \%$ & $63 \%$ \\
NSE & $13.3 \%$ & $80 \%$ & $48 \%$ & $40 \%$ \\
Ammonia & $33 \%$ & $67 \%$ & $50 \%$ & $50 \%$ \\
\hline
\end{tabular}

NPV, normal predictive value; PPV, positive predictive value.

Neuron-Specific Enolase

At study entry, $17 \%$ of all patients (5/30) revealed increased levels of NSE above the normal limit $(>17 \mathrm{ng} /$ $\mathrm{mL}$ ). In subjects with CHE, increased values were detected in $3 / 15$ patients (sensitivity 20\%) compared to $2 / 15$ patients with OHE (sensitivity 13\%). The follow-up of NSE mean values over the entire therapy duration of 6 days is shown in Figure 7. No significant correlation between NSE values during the LOLA treatment period of 6 days and different grades of HE severity could be shown. When calculating sensitivity, specificity and predictive values (PPV, NPV) for classification of CHE versus OHE in patients with $\mathrm{HE}$, cross-table with the corresponding measurements results for NSE (for a cut value of $17 \mathrm{ng}$ / $\mathrm{mL}$ ) revealed sensitivity of $20 \%$ and specificity of $80 \%$ (PPV 40\%, NPV 48\%; Table 3).

\section{Ammonia}

At baseline, serum ammonia levels $(>50 \mu \mathrm{mol} / \mathrm{L})$ were increased in 33\% (10/30) of all patients. Of those, CHE was diagnosed in $5 / 15$ patients compared to $5 / 15$ patients of those with OHE (sensitivity 33\%). After completion of LOLA therapy, pathologically elevated ammonia values were measured in $30 \%$ of patients. Mean ammonia values over time during the entire therapy duration of 6 days are shown in Figure 8. Multivariate analysis of all data over the 6-day study period revealed no significant changes in the time course while no differences between the different HE grades were observed. When calculating sensitivity, specificity and predictive values (PPV, NPV) for classification of $\mathrm{CHE}$ versus $\mathrm{OHE}$ in patients with $\mathrm{HE}$, crosstable with the corresponding measurements results for ammonia (for a cut value of $50 \mu \mathrm{g} / \mathrm{L}$ ) revealed sensitivity of $33 \%$ and specificity of $66.7 \%$ (PPV 50\%, NPV 50\%; Table 3). 


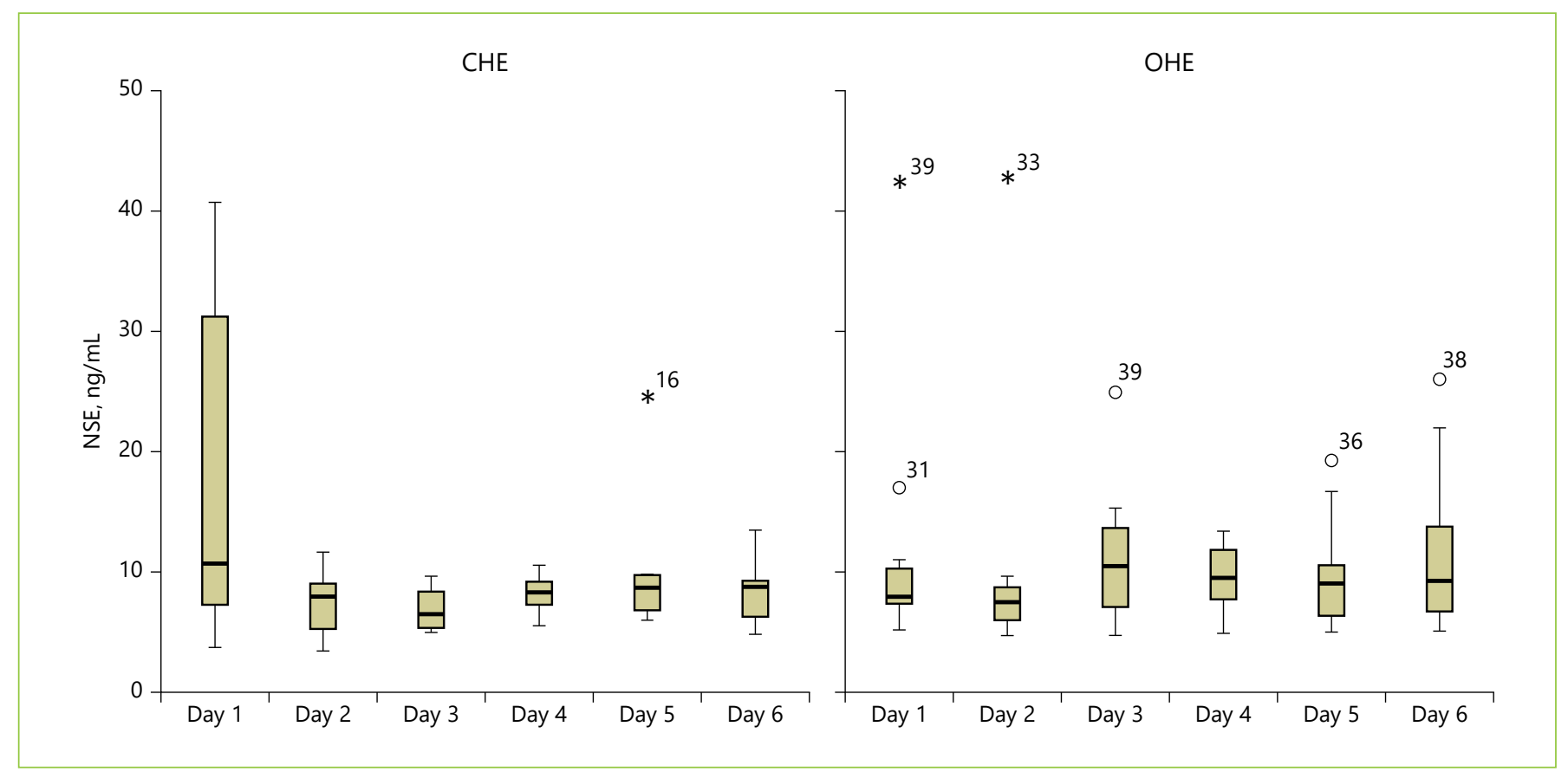

Fig. 7. Follow-up of NSE values showing median and standard deviation in patients with CHE and OHE from day 1-6 while receiving LOLA therapy.

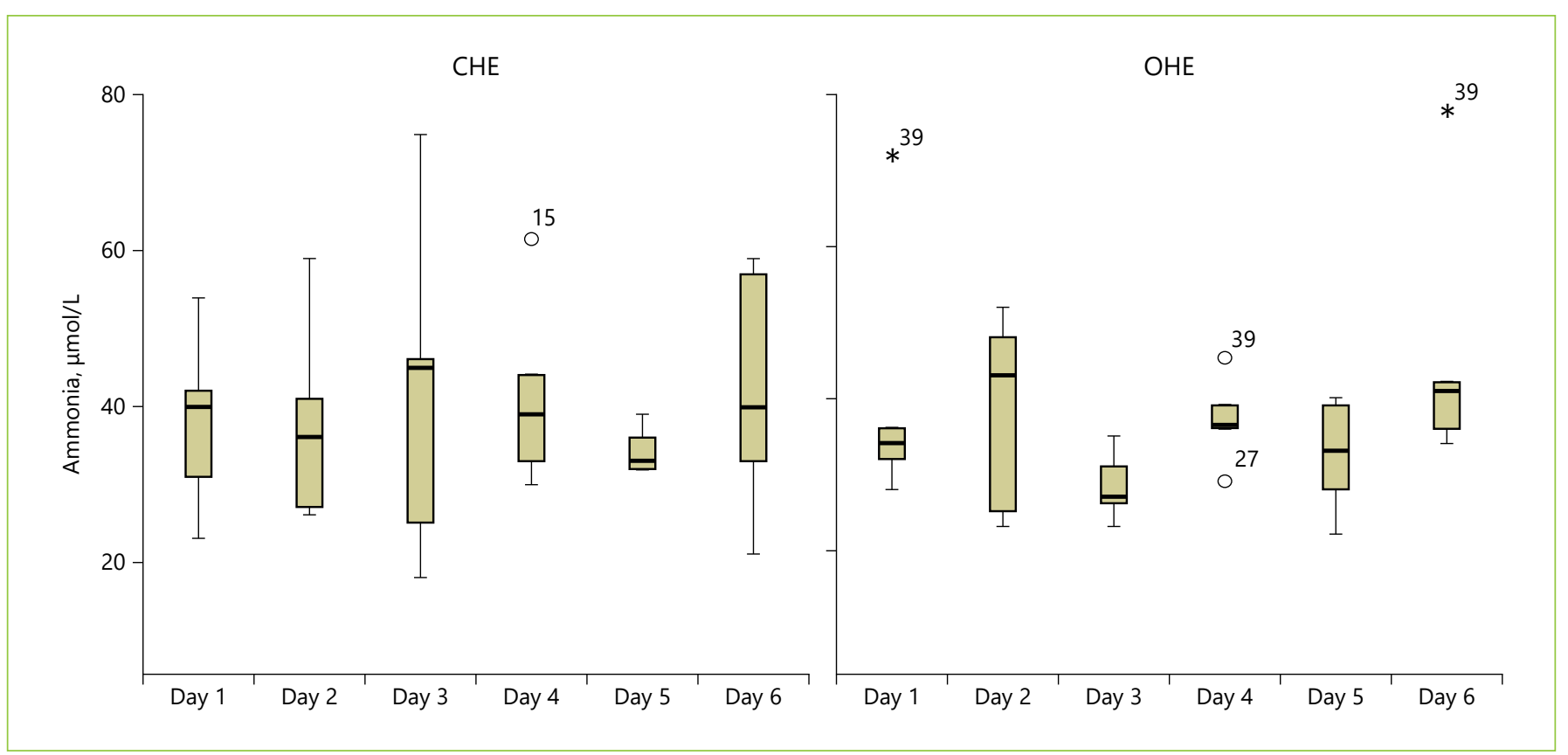

Fig. 8. Follow-up of NSE values showing median and standard deviation in patients with $\mathrm{CHE}$ and OHE from day 1-6 while receiving LOLA therapy. 
tients from the CHE group had a normal CFF $(>39 \mathrm{~Hz}$,

The current guideline of the German Society of Gastroenterology (Deutsche Gesellschaft für Verdauungskrankheiten und Stoffwechsel, DGVS) defining the treatment of complications of liver cirrhosis recommends a diagnosis of OHE by using clinical WHC. For diagnosis of CHE it recommends the application of CFF and/or PSE-testing [23].

Adequate therapy of $\mathrm{HE}$ is crucial to avoid events such as falls and traffic accidents, tendency to neglect, personality changes and difficulties in social and occupational life [20,23]. Current data from Germany suggest that $\mathrm{HE}$ is too rarely diagnosed in German hospitals [40]. Since a sufficient treatment of HE not only improves the quality of life but also patients' prognosis, screening for $\mathrm{HE}$ should be implemented into clinical routine in all cirrhotic patients [23]. Therefore, suitable laboratory parameters for detection and follow-up of HE are of particular importance.

The accuracy of ammonia determination is influenced by many factors including e.g. phlebotomy technique which should be always considered when interpreting results $[21,22]$. Thus, factors independent from liver dysfunction could affect ammonia levels (such as smoking or strong physical exercise) [22]. Therefore, plasma ammonia is considered as an invalid surrogate marker for $\mathrm{HE}$ $[5,22,23]$.

To date, there is no valid serum parameter which is recommended by current guidelines for detection and follow-up of HE in cirrhotic patients. Since there is an unmet need for diagnostic laboratory parameters for detection and monitoring of $\mathrm{HE}$ in patients with cirrhosis which are reliable and easy to perform, we performed this prospective study to evaluate an association of neuronal markers S-100-beta and NSE with the severity and course of HE while medical therapy with LOLA was applied for a period of 6 days in all patients suffering from HE. Our hypothesis was that S-100-beta and NSE may enable assessment and grading of HE in cirrhosis.

At study entry (before LOLA therapy was applied), CHE was diagnosed in $50 \%$ of all patients compared to OHE in $50 \%$ when using clinical WHC. At the end of the study (after therapy with LOLA for 6 days), WHC were improved in $46 \%$, unchanged in $50 \%$ and worsened in $4 \%$ (Fig. 4).

When defining a threshold value of $<39 \mathrm{~Hz}$ as pathological flicker frequency, HE could be detected by CFF in $80 \%$ of all patients with $\mathrm{CHE}$ (range $35-39 \mathrm{~Hz}$ ) and in $100 \%$ with OHE (range $25-35 \mathrm{~Hz}, p<0.01$ ). Only 3 pa-
36). At the end of study, CFF was improved in $79 \%$ of all patients while unchanged in $21 \%$, respectively.

Using PSE-testing, HE was diagnosed in $73 \%$ of all patients with CHE and in 100\% with OHE. Interestingly, pathological PSE-scores were found in 3 patients tested negative for $\mathrm{HE}$ by CFF. PSE-scores were significantly lower in the CHE group compared to the OHE group. However, there was an overlap of test results between the two groups: $63 \%$ of the measured values fell into an intersection between -8 (lowest value in the OHE group) and -12 (highest value in the CHE group). This result is supported by a large study, which also found a strong overlap of PSE-scores between different disease levels. PSE-testing showed an improvement in 30\% after LOLA-therapy, while in 59\% the test results were unchanged and in $11 \%$ deterioration could be observed [43].

When comparing the different diagnostic procedures for detection and follow-up of HE, CFF had the highest sensitivity both in patients with $\mathrm{CHE}$ and $\mathrm{OHE}$.

All biochemical parameters investigated in this study (S-100-beta, NSE, ammonia) showed no significant correlation with the severity of HE (as diagnosed by WHC, CFF and PSE-testing). In addition, the MVA did not reveal any significant change of the analyzed parameters over the treatment period of 6 days with LOLA and no significant correlation with the severity of $\mathrm{HE}$ after completion of drug therapy (Fig. 5a-c).

When comparing the validity of all serum markers, S100-beta showed the highest sensitivity for HE detection, although it was low at $63 \%$. The sensitivity of NSE was below $20 \%$ and was increased in only $17 \%$ of all patients with proven HE. The sensitivity of serum ammonia, which is frequently used in clinical routine, was only $33 \%$ in our study. None of the laboratory parameters was able to differentiate between $\mathrm{CHE}$ and OHE or suitable to document any therapeutical effect when compared with WHC, CFF and PSE-testing.

Our study showed for the first time that brain biomarkers S-100-beta and NSE do not significantly correlate with HE severity when using different proven diagnostic methods (CFF and PSE-testing). Furthermore, these neuromarkers do not represent reliable biochemical markers for a follow-up of HE under LOLA therapy.

To date, there is no routine laboratory parameter which represents a valid diagnostic alternative to psychometric and neurophysiologic diagnostic procedures including CFF and PSE-testing for detection and monitoring of HE in cirrhosis [44]. 
Patients had to sign a written consent to participate in this study. The study protocol was examined and approved by the Ethics Committee of the Klinikum Rechts der Isar (Project number 1547/06, Klinikum Rechts der Isar, Technical University of Munich).

\section{Disclosure Statement}

The authors have no conflicts of interest to declare.
None.

\section{Author Contributions}

H.S. and M.S. performed HE diagnostics and obtained laboratory parameters, B.H. contributed to statistical workup, W.S. and F.G. wrote the study protocol and the manuscript.

\section{References}

1 Amodio P, Del Piccolo F, Pettenò E, Mapelli $\mathrm{D}$, Angeli P, Iemmolo R, et al. Prevalence and prognostic value of quantified electroencephalogram (EEG) alterations in cirrhotic patients. J Hepatol. 2001 Jul;35(1):37-45.

2 Romero-Gómez M, Boza F, García-Valdecasas MS, García E, Aguilar-Reina J. Subclinical hepatic encephalopathy predicts the development of overt hepatic encephalopathy. Am J Gastroenterol. 2001 Sep;96(9):2718-23.

3 Montgomery JY, Bajaj JS. Advances in the evaluation and management of minimal hepatic encephalopathy. Curr Gastroenterol Rep. 2011 Feb;13(1):26-33.

4 Vilstrup H, Amodio P, Bajaj J, Cordoba J, Ferenci $\mathrm{P}$, Mullen KD, et al. Hepatic encephalopathy in chronic liver disease: 2014 Practice Guideline by the American Association for the Study of Liver Diseases and the European Association for the Study of the Liver. Hepatology. 2014 Aug;60(2):715-35.

5 Ferenci P, Lockwood A, Mullen K, Tarter R, Weissenborn K, Blei AT. Hepatic encephalopathy-definition, nomenclature, diagnosis, and quantification: final report of the working party at the 11th World Congresses of Gastroenterology, Vienna, 1998. Hepatology. 2002 Mar;35(3):716-21.

6 Lewis M, Howdle PD. The neurology of liver failure. QJM. 2003 Sep;96(9):623-33.

7 Poordad FF. Review article: the burden of hepatic encephalopathy. Aliment Pharmacol Ther. 2007 Feb;25 Suppl 1:3-9.

8 Randolph C, Hilsabeck R, Kato A, Kharbanda P, Li YY, Mapelli D, et al.; International Society for Hepatic Encephalopathy and Nitrogen Metabolism (ISHEN). Neuropsychological assessment of hepatic encephalopathy: ISHEN practice guidelines. Liver Int. 2009 May; 29(5):629-35

9 http://www.gbe- bund.de/gbe10/pkg_isgbe5. prc_isgbe?p_uid=gast $\&$ p_aid $=0 \&$ p sprache $=\mathrm{D}$ (accessed 1 Jan 2019).

10 Perumpail BJ, Khan MA, Yoo ER, Cholankeril G, Kim D, Ahmed A. Clinical epidemiology and disease burden of nonalcoholic fatty liver disease. World J Gastroenterol. 2017 Dec; 23(47):8263-76.
11 Bajaj JS, Hafeezullah M, Hoffmann RG, Saeian K. Minimal hepatic encephalopathy: a vehicle for accidents and traffic violations. Am J Gastroenterol. 2007 Sep;102(9):1903-9.

12 Kircheis G, Knoche A, Hilger N, Manhart F, Schnitzler A, Schulze H, et al. Hepatic encephalopathy and fitness to drive. Gastroenterology. 2009 Nov;137(5):1706-15.e1-9.

13 Shaw J, Bajaj JS. Covert Hepatic Encephalopathy: Can My Patient Drive? J Clin Gastroenterol. 2017 Feb;51(2):118-26.

14 Bajaj JS, Wade JB, Gibson DP, Heuman DM, Thacker LR, Sterling RK, et al. The multi-dimensional burden of cirrhosis and hepatic encephalopathy on patients and caregivers. Am J Gastroenterol. 2011 Sep;106(9):1646-53.

15 Groeneweg M, Quero JC, De Bruijn I, Hartmann IJ, Essink-bot ML, Hop WC, et al. Subclinical hepatic encephalopathy impairs daily functioning. Hepatology. 1998 Jul;28(1):459.

16 Bajaj JS, Hafeezullah M, Zadvornova Y, Martin E, Schubert CM, Gibson DP, et al. The effect of fatigue on driving skills in patients with hepatic encephalopathy. Am J Gastroenterol. 2009 Apr;104(4):898-905.

17 Jepsen P, Ott P, Andersen PK, Sørensen HT, Vilstrup H. Clinical course of alcoholic liver cirrhosis: a Danish population-based cohort study. Hepatology. 2010 May;51(5):1675-82.

18 Bass NM, Mullen KD, Sanyal A, Poordad F, Neff G, Leevy CB, et al. Rifaximin treatment in hepatic encephalopathy. N Engl J Med. 2010 Mar;362(12):1071-81.

19 Mohammad RA, Regal RE, Alaniz C. Combination therapy for the treatment and prevention of hepatic encephalopathy. Ann Pharmacother. 2012 Nov;46(11):1559-63.

20 Bajaj JS. Review article: the modern management of hepatic encephalopathy. Aliment Pharmacol Ther. 2010 Mar;31(5):537-47.

21 Gundling F, Seidl H, Schmidt T, Schepp W. Blood ammonia level in liver cirrhosis: a conditio sine qua non to confirm hepatic encephalopathy? Eur J Gastroenterol Hepatol. 2008 Mar;20(3):246-7.

22 Gundling F, Zelihic E, Seidl H, Haller B, Umgelter A, Schepp W, et al. How to diagnose hepatic encephalopathy in the emergency department. Ann Hepatol. 2013 Jan-Feb;12(1): 108-14.

23 Gerbes AL, Labenz J, Appenrodt B, Dollinger M, Gundling F, Gülberg V, et al; Deutsche Gesellschaft für Allgemein- und Viszeralchirurgie (DGAV); Deutsche Gesellschaft für Innere Medizin e.V. (DGIM); Deutsche Gesellschaft für Infektiologie e.V. (DGI); Deutsche Gesellschaft für Pathologie e.V./Bundesverband deutscher Pathologen e.V. (DGP/BDP); Deutsche Röntgengesellschaft e.V. (DRG); Deutsche Gesellschaft für Interventionelle Radiologie und minimal-invasive Therapie (DeGIR); Deutsche Gesellschaft für Nephrologie (DGFN); Deutsche Gesellschaft für Ultraschall in der Medizin (DEGUM); Deutsche Gesellschaft für Neurologie e.V. (DGN); Deutsche Gesellschaft für Ernährungsmedizin e.V. (DGEM); Lebertransplantierte Deutschland e.V; Collaborators: [Updated S2k-Guideline "Complications of liver cirrhosis". German Society of Gastroenterology (DGVS)]. Z Gastroenterol. 2019 May;57(5):e168.

24 Görg B, Schliess F, Häussinger D. Osmotic and oxidative/nitrosative stress in ammonia toxicity and hepatic encephalopathy. Arch Biochem Biophys. 2013 Aug;536(2):158-63.

25 McPhail MJ, Bajaj JS, Thomas HC, TaylorRobinson SD. Pathogenesis and diagnosis of hepatic encephalopathy. Expert Rev Gastroenterol Hepatol. 2010 Jun;4(3):365-78.

26 Bertsch T, Casarin W, Kretschmar M, Zimmer W, Walter S, Sommer C, et al. Protein S-100B: a serum marker for ischemic and infectious injury of cerebral tissue. Clin Chem Lab Med. 2001 Apr;39(4):319-23.

27 Wang KK, Yang Z, Zhu T, Shi Y, Rubenstein $\mathrm{R}$, Tyndall JA, et al. An update on diagnostic and prognostic biomarkers for traumatic brain injury. Expert Rev Mol Diagn. 2018 Feb; 18(2):165-80.

28 Stelzl T, von Bose MJ, Hogl B, Fuchs HH, Flugel KA. A comparison of the prognostic value of neuron-specific enolase serum levels and somatosensory evoked potentials in 13 reanimated patients. Eur J Emerg Med. 1995 Mar; 2(1):24-7. 
29 Donato R. S-100 proteins. Cell Calcium. 1986 Jun; 7(3):123-45.

30 Wiltfang J, Nolte W, Otto M, Wildberg J, Bahn E, Figulla HR, et al. Elevated serum levels of astroglial S100beta in patients with liver cirrhosis indicate early and subclinical portalsystemic encephalopathy. Metab Brain Dis. 1999 Dec;14(4):239-51.

31 Saleh A, Kamel L, Ghali A, Ismail A, El Khayat H. Serum levels of astroglial S100-beta and neuron-specific enolase in hepatic encephalopathy patients. East Mediterr Health J. 2007 Sep-Oct;13(5):1114-23.

32 Duarte-Rojo A, Ruiz-Margáin A, Macias-Rodriguez RU, Cubero FJ, Estradas-Trujillo J, Muñoz-Fuentes RM, et al. Clinical scenarios for the use of $S 100 \beta$ as a marker of hepatic encephalopathy. World J Gastroenterol. 2016 May;22(17):4397-402.

33 Toney NA, Bell MJ, Belle SH, Hardison RM, Rodriguez-Baez N, Loomes KM, et al.; Pediatric Acute Liver Failure Study Group. Hepatic Encephalopathy in Children With Acute Liver Failure: Utility of Serum Neuromarkers. J Pediatr Gastroenterol Nutr. 2019 Jul;69(1): 108-15.
34 Butterworth RF, Kircheis G, Hilger N, McPhail MJ. Efficacy of 1-ornithine l-aspartate for the treatment of hepatic encepha-lopathy and hyperammonemia in cirrhosis: systematic review and meta-analysis of randomized controlled trials. J Clin Exp Hepatol. 2018 Sep;8(3):301-13.

35 Kircheis G, Wettstein M, Timmermann L, Schnitzler A, Häussinger D. Critical flicker frequency for quantification of low-grade hepatic encephalopathy. Hepatology. $2002 \mathrm{Feb}$ 35(2):357-66

36 Weissenborn K, Ennen JC, Schomerus H, Rückert N, Hecker H. Neuropsychological characterization of hepatic encephalopathy. J Hepatol. 2001 May;34(5):768-73.

37 Weissenborn K, Rückert N, Hecker H, Manns MP. The number connection tests A and B: interindividual variability and use for the assessment of early hepatic encephalopathy. J Hepatol. 1998 Apr;28(4):646-53.

38 Schomerus H, Hamster W. Neuropsychological aspects of portal-systemic encephalopathy. Metab Brain Dis. 1998 Dec;13(4):361-77.

39 Weissenborn K, Scholz M, Hinrichs H, Wiltfang J, Schmidt FW, Künkel H. Neurophysiological assessment of early hepatic encephalopathy. Electroencephalogr Clin Neurophysiol. 1990 Apr;75(4):289-95.
40 Labenz C, Wörns MA, Schattenberg JM, Huber Y, Galle PR, Labenz J; ALGK study group. Epidemiology of hepatic encephalopathy in german hospitals - the EpHE study. Z Gastroenterol. 2017 Aug;55(8):741-7.

41 Strauss GI, Christiansen M, Møller K, Clemmesen JO, Larsen FS, Knudsen GM. S-100b and neuron-specific enolase in patients with fulminant hepatic failure. Liver Transpl. 2001 Nov;7(11):964-70.

42 Groeneweg M, de Knegt RJ, Hamberger A, Ding M, Wang S, Schalm SW, et al. Neuronal and glial marker proteins in encephalopathy associated with acute liver failure and acute hyperammonemia in the rabbit. Metab Brain Dis. 1993 Jun;8(2):95-106.

43 Kircheis G, Hilger N, Häussinger D. Value of critical flicker frequency and psychometric hepatic encephalopathy score in diagnosis of low-grade hepatic encephalopathy. Gastroenterology. 2014 Apr;146(4):961-9.

44 Weissenborn K. Hepatic Encephalopathy: Definition, Clinical Grading and Diagnostic Principles. Drugs. 2019 Feb;79(1 Suppl 1):5- 